\title{
The Effect of Fluence Variations of Nd:YAG Laser Ablation and Sample Condition on Human Tooth
}

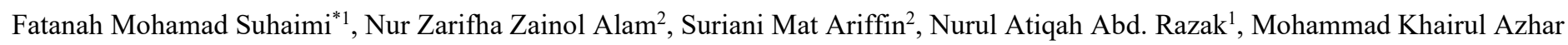
Abdul Razab ${ }^{3}$

${ }^{1}$ Craniofacial and Biomaterial Sciences Cluster, Advanced Medical and Dental Institute, Universiti Sains Malaysia, Bertam, 13200 Kepala Batas, Penang, Malaysia

${ }^{2}$ School of Physics, Universiti Sains Malaysia, 11800 Gelugor, Penang, Malaysia

${ }^{3}$ School of Health Science, Universiti Sains Malaysia, Health Campus, 16150 Kubang Kerian, Kelantan, Malaysia

\author{
A R T I C L E IN F O \\ Article history: \\ Received: 14 August, 2018 \\ Accepted: 11 October, 2018 \\ Online: 18 October, 2018
}

Keywords:

Enamel

Laser ablation

Nd:YAG laser

\begin{abstract}
A B S T R A C T
Nd:YAG laser has shown some potential to be used in dental practice replacing the conventional method. In particular, it can be used to modify the tooth surface by the ablation process. The laser provides an ability to accurately deliver a significant amount of energy into a confined region. Thus, alteration of the sample surface and composition may occur during the process. Additionally, the use of a laser in ablation procedure is also associated with heat generation and potential thermal injury that may be experienced by a patient. The wet condition of the samples is expected to reduce the thermal effect. In this paper, the changes of enamel surface and elemental composition following laser irradiation of Nd:YAG laser are discussed. The teeth samples were irradiated at $1.5 \mathrm{~Hz}$ of pulse rate, $100 \mathrm{~ms}$ of pulse width, and range of fluences of 80-120 J/cm ${ }^{2}$. Field Emission Scanning Microscopy (FESEM) and Energy Dispersive X-ray (EDX) were used to analyze the morphology and composition of the teeth samples. Samples were compared before and after laser irradiation. The percentages of carbon increased after laser irradiation, while oxygen decreased for most of the samples. The morphologies of the samples were varied with a more pronounced effect on the sample surface at higher fluence. In addition, the effect of wet sample condition is also investigated and discussed. It is demonstrated that the ablation in wet condition produced less damage to the enamel surface compared to dry sample. However, no remarkable difference between the elemental composition of wet and dry samples.
\end{abstract}

\section{Introduction}

Laser has been successfully used in dental applications such as for caries prevention, etching bond strength, restorative procedure, gum recontouring, and surgical procedure [1-3]. Research on medical laser in dental practice has been conducted for several years to investigate the potential and suitability of laser devices and its parameters for replacing the conventional method. However, careful consideration has to be made on selecting parameter settings, types of laser, wavelength, energy, pulse duration, absorption properties and scattering effect. In particular, the interactions of the laser with tissues are pivotal for selecting laser

*Fatanah M. Suhaimi, Craniofacial and Biomaterial Sciences Cluster, Advanced Medical and Dental Institute, Universiti Sains Malaysia, 13200 Kepala Batas,

Penang, Malaysia.+6045622561, fatanah.suhaimi@usm.my system and operating procedure that will best suit the application in dentistry.

A laser is categorized into four types depending on the medium used, whether it is a liquid, solid-state, gas and semi-conductor. Among all types of laser, Nd:YAG is commonly used in dentistry. The first pulsed Nd:YAG laser was released in 1990 specifically for the dental market [1]. Common laser parameters include fluence, pulse width and pulse rate. Fluence is the optical energy per unit area. Whereas, the pulse width can be defined as the amount of time the laser releases its energy or emits the laser pulse. Pulse rate indicates the number of pulses emitted per second.

In dentistry, $\mathrm{Nd}$ :YAG laser has been used for caries prevention [3], germ removal, and modify the bond strength and surface treatment $[4,5]$. Nd:YAG laser possesses a suitable wavelength for 


\section{F.M. Suhaimi et al. / Advances in Science, Technology and Engineering Systems Journal Vol. 3, No. 5, 398-406 (2018)}

high diffusion through hydroxyapatite and water, and soft tissue due to its behaviour of having high penetration depth [6]. Additionally, pre-treatment by Nd:YAG laser irradiation of etchand-rinse adhesive appeared to have a positive effect on the adhesive-dentin bonding [5]. An in-vitro study by Beketova et al. suggested that $\mathrm{Nd}$ :YAG laser has potential in inducing bioactivity of dental ceramic [7].

Eventhough many research had shown the positive effect of using Nd:YAG laser, the impact toward the exposed tissues need to be considered to avoid damage and deterioration of the tissue. Issues related to the ablation process of dental tissue include irregular surface modification, charring, and peripheral cracks [8]. These issues are also associated with dry ablation. An alternative method by lasers for dental ablation characterize the risk involved such as thermal damage experience by patient compare to traditional cavity preparation methods. Moreover, heat generation is crucial as it may lead to painful sensations and potential thermal injury [8-11].

Laser ablation requires sufficient energy to remove material from the tooth by ejecting the electrons from its atom. A study by Cecchini et al. reported that dimineralization of enamel occurs after laser irradiation. Change in morphology is indicated with cracks and crater presence after irradiation [12]. In addition, a research conducted by Khatavkar and Hegde found that Er:YAG laser cause an etching effect on a surface that is comparable to conventional acid etching [13]. Increasing the energy parameters produced a difference surface morphology of enamel from roughening to an etching-like micro-roughen pattern based on a Field Emission Scanning Electron Microscope (FESEM) evaluation.

Histological evaluation on the efficiency of employing ultrashort pulsed laser in dentin and enamel caries removal provided the positive result as no morphological changes and no side effect indicated in the healthy areas of dentin and enamel [89]. On the other hand, morphological studies on enamel and dentin irradiated with $\mathrm{Nd}$ :YAG laser with different energy densities shows that enamel exhibits shallow crater than dentin due to the fact of varying composition between them. Enamel tissues are found to be more calcified, tight and hard which promotes fissures due to sudden heat distribution throughout the surface. However, the high number of shots resulted in significant changes in morphology with total eradication of smear layer [14].

Besides, the elemental composition of the enamel may also be altered due to the laser irradiation subjected to the sample. According to Al-Hadeethi et al., 2016, radiation by high energy laser melts the enamel surface, which then increased energy density, and thus increases carbon element [15]. Moreover, photothermal evaporation during laser irradiation caused a reduction of water molecules [16]. The changes in water molecules may be assessed by examining the oxygen composition. Interestingly, calcium, phosphorus, and the $\mathrm{Ca} / \mathrm{P}$ ratio in the sample indicate the hardness of the tooth.

The condition of the sample whether dry or wet plays an important role towards the surface produced after the ablation process. A study by Bartoli et al. on stone cleaning application indicates that ablation in wet condition is more efficient due to vaporization process of water molecules [17]. This statement is also supported by a study conducted on a wet film that suggests the wet condition has less resistant to the laser irradiation [18]. Thus, thermal conductivity, heat transfer and vaporization process that occur during the ablation process may result in different morphological changes of the tooth samples.

This research was done to investigate the effect of $\mathrm{Nd}: \mathrm{YAG}$ laser fluences on the enamel of the human tooth. Other laser parameters such as pulse width and pulse rate were kept constant. Surface morphology and elemental composition of the enamel were analysed before and after laser irradiation. Additionally, the condition of the sample whether wet or dry is also examined to identify the differences outcome of the laser ablation process. This paper is an extension of work originally presented in the $39^{\text {th }}$ International Conference of IEEE Engineering in Medicine and Biology Society [19].

\section{Methods}

\subsection{Sample Preparation}

In this study, seven premolar human teeth were used as the sample. Teeth were collected from the dental clinic of the Advanced Medical and Dental Institute (AMDI), Universiti Sains Malaysia (USM) in Penang, Malaysia. The collected samples were stored individually in a plastic container containing normal saline. Samples were carefully selected, and only healthy teeth were used for the study. Ethical approval for this study has been obtained from the Human Research Ethics Committee of Universiti Sains Malaysia.

Debris on the teeth was removed using a brush and cleaned using water. Then, the cleaned tooth was cut into two using an IsoMet Low-Speed Saw, (Buehler, US). After that, the tooth was mounted in a designated container, and the surface of the mounting was covered with a mixture of resin and hardener. The amount of the resin and the hardener were measured carefully by volume. The sample surface was then polished using a grinding and polishing machine, MetaServ 250 Grinder Polisher (Buehler, Germany). During the grinding procedure, a rotating disk of abrasive paper was used, and it was flushed simultaneously with a coolant to remove debris and minimize the heat.

\subsection{Laser Irradiation}

Seven premolar teeth were used in this study. Samples were irradiated with Nd:YAG laser (Cynosure, US) at a wavelength of $1064 \mathrm{~nm}$. A $5 \mathrm{~mm}$ laser tip was used. The teeth were irradiated with a fluence of $80,90,100,110$, and $120 \mathrm{~J} / \mathrm{cm}^{2}$, a pulse rate of $1.5 \mathrm{~Hz}$, and a pulse width of $100 \mathrm{~ms}$. One sample was irradiated for each fluence. Thus, a total of five samples were irradiated in dry condition. The distance of the laser tip was kept constant during the irradiation procedure to ensure a consistent spot size on the enamel surface.

\subsection{Sample Analysis}

Electron Dispersive X-ray Spectrometer (EDX) and FESEM were used to analyse the samples. The image of the sample was captured, and the morphological analysis was made using the FESEM at several magnifications. The elemental composition in terms of atomic percentage and weight percentage was recorded using the EDX system. The morphology and data on the elemental 
composition of the samples were compared before and after laser irradiation.

\subsection{Sample Condition}

Wet samples were also tested to investigate whether the samples produce different morphology compared to the dry samples. Water spray was applied onto the sample surface before the irradiation process. Two samples were irradiated in the wet condition.

\section{Results and Discussion}

\subsection{Effect of Fluence Variations}

The morphology of the enamel surface had been captured before and after laser irradiation with different fluence energies applied to each sample. Figure 1 shows the surface morphology of tooth sample before and after laser irradiation with $80 \mathrm{~J} / \mathrm{cm}^{2}$ at 5000x magnification. The surface appeared rough and nonuniform with large bubbles present after irradiation as compared to before irradiation.

Table 1 presents the identified elements by atomic and weight percentages before and after laser irradiation at $80 \mathrm{~J} / \mathrm{cm}^{2}$. In this table, $\mathrm{C}$ is carbon, $\mathrm{O}$ is oxygen, $\mathrm{Na}$ is sodium, $\mathrm{P}$ is phosphorus, $\mathrm{Cl}$ is chlorine, $\mathrm{Ca}$ is calcium, and $\mathrm{Si}$ is silicon. Carbon had the highest atomic percentage after irradiation $(54.38 \%)$ followed by oxygen $(28.20 \%)$. Similarly, the weight percentages were $37.78 \%$ and $26.10 \%$, respectively. Interestingly, oxygen was the highest element before irradiation. Elements such as $\mathrm{Na}, \mathrm{P}$, and $\mathrm{Cl}$ were not largely affected after laser irradiation since the atomic and weight percentages were muchly smaller compared to other elements.

Table 1: Identified elements by atomic percentage and weight percentage, before and after laser irradiation at $80 \mathrm{~J} / \mathrm{cm}^{2}$.

\begin{tabular}{|c|c|c|c|c|}
\hline Element & \multicolumn{2}{|c|}{ Before Irradiation } & \multicolumn{2}{c|}{ After Irradiation } \\
\hline & Atomic & Weight & Atomic & Weight \\
\hline $\mathrm{C}$ & 13.31 & 7.24 & 54.38 & 37.78 \\
\hline $\mathrm{O}$ & 53.87 & 39.02 & 28.20 & 26.10 \\
\hline $\mathrm{Na}$ & 0.65 & 0.68 & 0.40 & 0.54 \\
\hline $\mathrm{P}$ & 12.48 & 17.51 & 6.09 & 10.92 \\
\hline $\mathrm{Cl}$ & 0.70 & 1.13 & 0.62 & 1.25 \\
\hline $\mathrm{Ca}$ & 18.97 & 34.42 & 9.61 & 22.27 \\
\hline $\mathrm{Si}$ & - & - & 0.70 & 1.14 \\
\hline Total & 100.00 & 100.00 & 100.00 & 100.00 \\
\hline
\end{tabular}

Figure 2 shows the surface morphology of the tooth sample before and after laser irradiation with $90 \mathrm{~J} / \mathrm{cm}^{2}$ at $5000 \mathrm{x}$ magnification. The image consists of large indentations with less bubbles evenly disperse throughout the surface. However, more bubbles were present, and the surface appeared rough after being irradiated by laser at $90 \mathrm{~J} / \mathrm{cm}^{2}$, indicating that the resulted surface had more damages as compared to the sample in Figure 1. However, the surface of the sample before irradiation as shown in the left panel appeared scalier compared to the first sample in Figure 1.
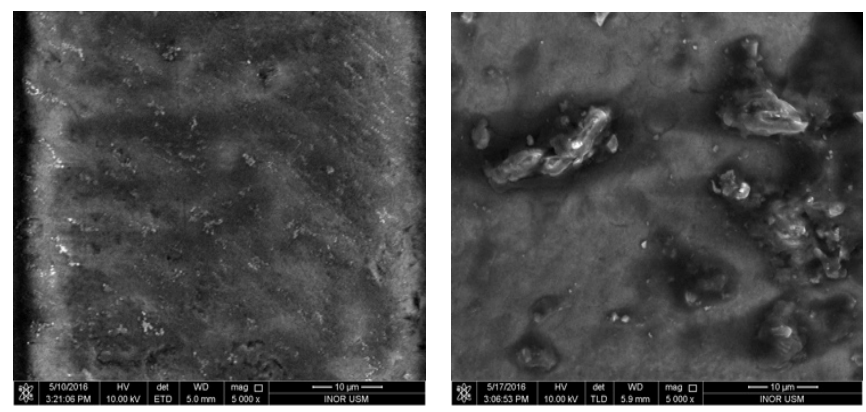

Figure 1: Surface morphology of tooth sample before (left) and after laser irradiation (right) of $80 \mathrm{~J} / \mathrm{cm}^{2}$ at $5000 \mathrm{x}$ magnification.
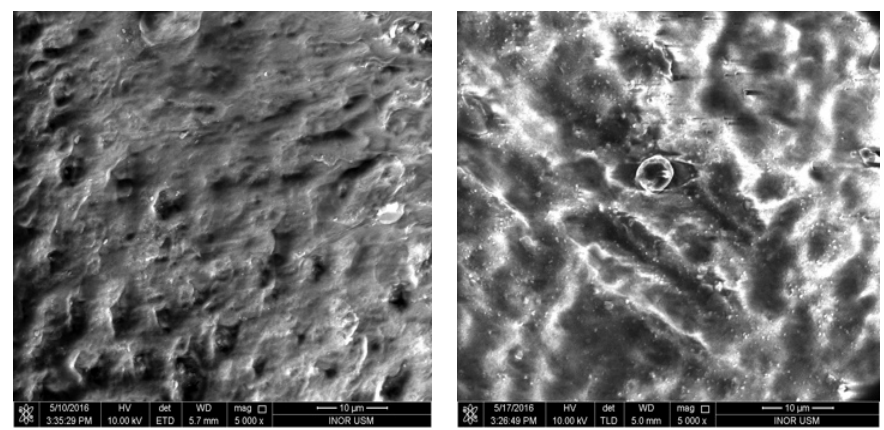

Figure 2: Surface morphology of tooth sample before (left) and after laser irradiation (right) of $90 \mathrm{~J} / \mathrm{cm}^{2}$ at 5000x magnification.

Table 2 presents the identified elements by atomic and weight percentages before and after laser irradiation at $90 \mathrm{~J} / \mathrm{cm}^{2}$. Oxygen, phosphorus, and calcium decreased in both atomic and weight percentages. The percentage difference of weight changes were less than $12 \%$ individually for oxygen, phosphorus, and calcium. The highest element after irradiation was oxygen, eventhough oxygen slightly decreased after irradiation. Nevertheless, carbon increased after the irradiation, from $21.33 \%$ to $38.85 \%$ of atomic percentage. Chlorine and silicon were not extremely modified by the irradiation.

The surface morphology of tooth sample before and after laser irradiation with $100 \mathrm{~J} / \mathrm{cm}^{2}$ at $5000 \mathrm{x}$ magnification is shown in Figure 3. Enamel surface appears smooth and shiny with evenly choppy texture. Nonetheless, the appearance of the enamel changed after laser irradiation resulting in a rough, and an uneven bubble distribution on the surface of the sample.

Table 3 presents the identified elements by atomic and weight percentages before and after laser irradiation at $100 \mathrm{~J} / \mathrm{cm}^{2}$. In this table, $\mathrm{Al}$ is aluminium. Oxygen, phosphorus and calcium decreased significantly while carbon increased by almost triple the value before irradiation. The atomic percentage of oxygen was largely reduced, which was from $52.26 \%$ to $36.68 \%$. Other elements were not significantly changed.

The tooth sample before and after laser irradiation with 110 $\mathrm{J} / \mathrm{cm}^{2}$ at 5000x magnification is shown in Figure 4. The surface appears uniform and rough with fewer indentations before laser irradiation. However, cracks and non-uniform surface were presented after exposing the sample to laser irradiation. 
F.M. Suhaimi et al. / Advances in Science, Technology and Engineering Systems Journal Vol. 3, No. 5, 398-406 (2018)

Table 2: Identified elements by atomic percentage and weight percentage, before and after laser irradiation at $90 \mathrm{~J} / \mathrm{cm}^{2}$.

\begin{tabular}{|c|c|c|c|c|}
\hline Element & \multicolumn{2}{|c|}{ Before Irradiation } & \multicolumn{2}{c|}{ After Irradiation } \\
\hline & Atomic & Weight & Atomic & Weight \\
\hline $\mathrm{C}$ & 21.33 & 12.44 & 38.85 & 25.13 \\
\hline $\mathrm{O}$ & 51.89 & 40.31 & 40.01 & 34.48 \\
\hline $\mathrm{Na}$ & - & - & 0.74 & 0.92 \\
\hline $\mathrm{P}$ & 10.21 & 15.36 & 7.57 & 12.63 \\
\hline $\mathrm{Cl}$ & 0.42 & 0.71 & 0.53 & 1.01 \\
\hline $\mathrm{Ca}$ & 15.70 & 30.56 & 11.20 & 24.17 \\
\hline $\mathrm{Si}$ & 0.45 & 0.62 & 1.10 & 1.66 \\
\hline Total & 100.00 & 100.00 & 100.00 & 100.00 \\
\hline
\end{tabular}

Table 3: Identified elements by atomic percentage and weight percentage, before and after laser irradiation at $100 \mathrm{~J} / \mathrm{cm}^{2}$.

\begin{tabular}{|c|c|c|c|c|}
\hline Element & \multicolumn{2}{|c|}{ Before Irradiation } & \multicolumn{2}{c|}{ After Irradiation } \\
\hline & Atomic & Weight & Atomic & Weight \\
\hline $\mathrm{C}$ & 18.66 & 10.63 & 44.37 & 30.19 \\
\hline $\mathrm{O}$ & 52.26 & 39.63 & 36.68 & 33.25 \\
\hline $\mathrm{Na}$ & 0.63 & 0.68 & 0.55 & 0.71 \\
\hline $\mathrm{P}$ & 11.57 & 16.99 & 7.66 & 13.45 \\
\hline $\mathrm{Cl}$ & - & - & 0.48 & 0.96 \\
\hline $\mathrm{Ca}$ & 16.88 & 32.07 & 7.59 & 17.24 \\
\hline $\mathrm{Si}$ & - & - & 1.91 & 3.04 \\
\hline $\mathrm{Al}$ & - & - & 0.76 & 1.16 \\
\hline $\mathrm{Total}$ & 100.00 & 100.00 & 100.00 & 100.00 \\
\hline
\end{tabular}
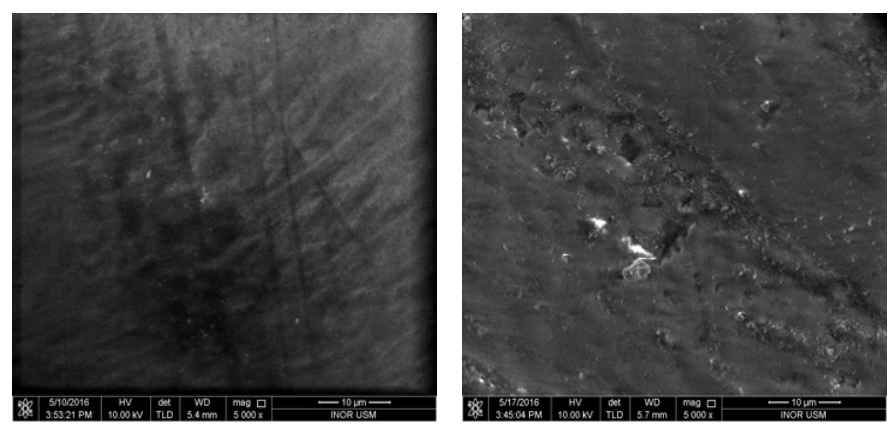

Figure 3: Surface morphology of tooth sample before (left) and after laser irradiation (right) of $100 \mathrm{~J} / \mathrm{cm}^{2}$ at $5000 \mathrm{x}$ magnification.

Table 4 presents the identified elements by atomic and weight percentages of the tooth sample before and after laser irradiation at $110 \mathrm{~J} / \mathrm{cm}^{2}$. The percentages of carbon, oxygen, and sodium reduced after laser irradiation. However, the change in oxygen was very light compared to the changes in carbon. Both atomic and weight percentages of phosphorus and calcium were increased. Yet, the changes in calcium were profound compared to phosphorus. Chlorine and silicon were not detected before irradiation but appeared after irradiation with a very small percentage.
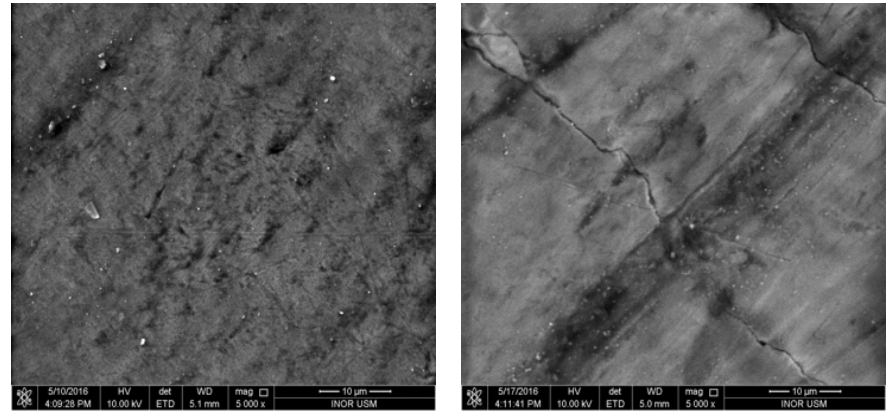

Figure 4: Surface morphology of tooth sample before (left) and after laser irradiation (right) of $110 \mathrm{~J} / \mathrm{cm}^{2}$ at $5000 \mathrm{x}$ magnification.
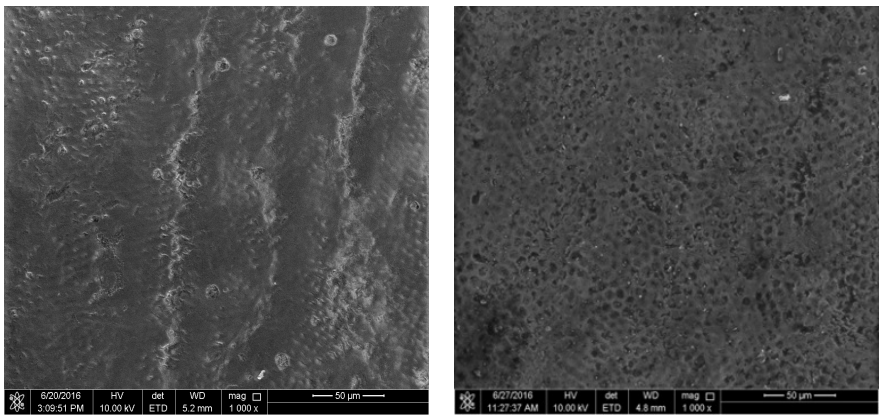

Figure 5: Surface morphology of tooth sample before (left) and after laser irradiation (right) of $120 \mathrm{~J} / \mathrm{cm}^{2}$ at $1000 x$ magnification.

Figure 5 shows the surface morphology of a tooth sample before after laser irradiation at $120 \mathrm{~J} / \mathrm{cm}^{2}$ at $1000 \mathrm{x}$ magnification and 500x magnification, respectively. The surface of the sample before irradiation was scaly and uneven. Nevertheless, the surface appeared even with tiny hollows after laser irradiation.

Table 4: Identified elements by atomic percentage and weight percentage, before and after laser irradiation at $110 \mathrm{~J} / \mathrm{cm}^{2}$.

\begin{tabular}{|c|c|c|c|c|}
\hline Element & \multicolumn{2}{|c|}{ Before Irradiation } & \multicolumn{2}{c|}{ After Irradiation } \\
\hline & Atomic & Weight & Atomic & Weight \\
\hline $\mathrm{C}$ & 35.76 & 23.68 & 26.18 & 15.21 \\
\hline $\mathrm{O}$ & 45.66 & 40.28 & 45.26 & 35.01 \\
\hline $\mathrm{Na}$ & 0.55 & 0.70 & 0.41 & 0.45 \\
\hline $\mathrm{P}$ & 8.94 & 15.26 & 11.19 & 16.76 \\
\hline $\mathrm{Cl}$ & - & - & 0.32 & 0.56 \\
\hline $\mathrm{Ca}$ & 9.09 & 20.08 & 16.23 & 31.45 \\
\hline $\mathrm{Si}$ & - & - & 0.41 & 0.56 \\
\hline Total & 100.00 & 100.00 & 100.00 & 100.00 \\
\hline
\end{tabular}

Table 5 compares the elemental compositions of a tooth sample before laser irradiation and after laser irradiation of $120 \mathrm{~J} / \mathrm{cm}^{2}$. In this table, $\mathrm{Mg}$ is magnesium. Before irradiation, oxygen has the highest atomic percentage with $38.29 \%$, followed by calcium with $28.15 \%$, phosphorus with $16.38 \%$, and carbon with $16.24 \%$. The 
highest weight percentage is calcium with $45.68 \%$, followed by oxygen, phosphorus, and carbon. Carbon and oxygen increased after laser irradiation. However, other elements decreased after laser irradiation. The percentages of silicon, sodium, magnesium and chlorine were considered not significant compared to other elements in this sample.

Table 5: Identified elements by atomic percentage and weight percentage, before and after laser irradiation at $120 \mathrm{~J} / \mathrm{cm}^{2}$.

\begin{tabular}{|c|c|c|c|c|}
\hline Element & \multicolumn{2}{|c|}{ Before Irradiation } & \multicolumn{2}{c|}{ After Irradiation } \\
\hline & Atomic & Weight & Atomic & Weight \\
\hline $\mathrm{C}$ & 16.24 & 7.90 & 35.70 & 22.32 \\
\hline $\mathrm{O}$ & 38.29 & 24.81 & 40.74 & 33.92 \\
\hline $\mathrm{Na}$ & 0.54 & 0.50 & 0.30 & 0.36 \\
\hline $\mathrm{P}$ & 16.38 & 20.54 & 8.52 & 13.72 \\
\hline $\mathrm{Cl}$ & 0.40 & 0.57 & 0.37 & 0.69 \\
\hline $\mathrm{Ca}$ & 28.15 & 45.68 & 12.84 & 26.79 \\
\hline $\mathrm{Si}$ & - & - & 1.33 & 1.95 \\
\hline $\mathrm{Mg}$ & - & - & 0.20 & 0.25 \\
\hline Total & 100.00 & 100.00 & 100.00 & 100.00 \\
\hline
\end{tabular}

\subsection{Effect of Wet Sample Condition}

Figure 6 shows the surface morphology of the tooth sample before and after laser irradiation of $80 \mathrm{~J} / \mathrm{cm}^{2}$ at a wet condition. The surface after laser irradiation at a wet condition appeared more uniform with tiny holes presented. Additionally, Table 6 compares the identified elements by atomic percentage and the weight percentage of the tooth sample before and after laser irradiation of $80 \mathrm{~J} / \mathrm{cm}^{2}$ at the wet condition. In this table, C is carbon, $\mathrm{O}$ is oxygen, $\mathrm{Na}$ is sodium, $\mathrm{P}$ is phosphorus, $\mathrm{Ca}$ is calcium, $\mathrm{Si}$ is silicon, and $\mathrm{Mg}$ is magnesium.

Oxygen was the highest element before irradiation, followed by calcium and phosphorus. After laser irradiation, the atomic percentage of oxygen reduced significantly while slight changes can be observed in the weight percentage. On the other hand, carbon increased massively to almost six times of its atomic percentage and nine times of its weight percentage, becoming the highest element exist in the sample. Phosphorus and calcium were also decreased after laser irradiation. Silicon was not detected before irradiation, but appeared after irradiation with a very small percentage. Nevertheless, sodium and magnesium were not found in the sample after irradiation.

Figure 7 presents the surface morphology of a tooth sample before and after laser irradiation of $110 \mathrm{~J} / \mathrm{cm}^{2}$ at a wet condition with a magnification of $1000 x$, and $500 x$, respectively. The sample appears uniform, smooth and without crack formation. Additionally, Table 7 shows the identified elements by atomic percentage and weight percentage before irradiation and after laser irradiation of $110 \mathrm{~J} / \mathrm{cm}^{2}$ at the wet condition.

Oxygen was the highest element in the sample before irradiation and after laser irradiation, eventhough it was largely decreased after irradiation. Additionally, carbon also decreased after laser irradiation. Other elements include sodium, phosphorus, and calcium were increased after laser irradiation. However, the increased in calcium was significant compared to the changes in phosphorus and sodium. Chlorine and silicon were not detected before irradiation but appeared after irradiation with a very small percentage.
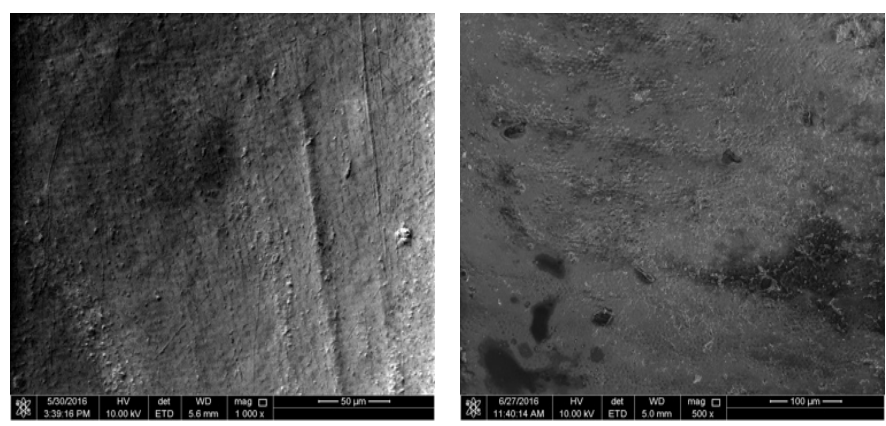

Figure 6: Surface morphology of the tooth sample before laser irradiation (left) at 1000x magnification and after laser irradiation with $80 \mathrm{~J} / \mathrm{cm}^{2}$ at wet condition (right) at 500x magnification.
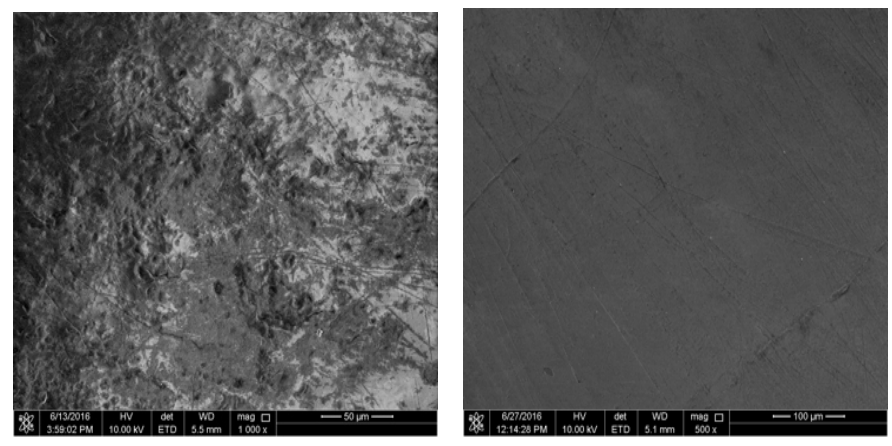

Figure 7: Surface morphology of the tooth sample before laser irradiation (left) at 1000x magnification and after irradiation with $110 \mathrm{~J} / \mathrm{cm}^{2}$ at wet condition (right) at 500x magnification.

Table 6: Identified elements by atomic percentage and weight percentage, before and after laser irradiation of $80 \mathrm{~J} / \mathrm{cm}^{2}$ with wet condition.

\begin{tabular}{|c|c|c|c|c|}
\hline Element & \multicolumn{2}{|c|}{ Before Irradiation } & \multicolumn{2}{c|}{ After Irradiation } \\
\hline & Atomic & Weight & Atomic & Weight \\
\hline $\mathrm{C}$ & 8.66 & 4.87 & 49.12 & 38.46 \\
\hline $\mathrm{O}$ & 62.60 & 46.88 & 43.59 & 45.46 \\
\hline $\mathrm{Na}$ & 0.54 & 0.59 & - & - \\
\hline $\mathrm{P}$ & 11.90 & 17.26 & 4.28 & 8.63 \\
\hline $\mathrm{Ca}$ & 16.06 & 30.14 & 2.47 & 6.47 \\
\hline $\mathrm{Si}$ & - & - & 0.54 & 0.98 \\
\hline $\mathrm{Mg}$ & 0.24 & 0.26 & - & \\
\hline Total & 100.00 & 100.00 & 100.00 & 100.00 \\
\hline
\end{tabular}

Figure 8 presents the bar charts on atomic and weight percentage of $\mathrm{C}, \mathrm{O}, \mathrm{P}$ and $\mathrm{Ca}$ before irradiation on the top panel and after laser irradiation of $80 \mathrm{~J} / \mathrm{cm}^{2}, 90 \mathrm{~J} / \mathrm{cm}^{2}, 100 \mathrm{~J} / \mathrm{cm}^{2}, 110$ $\mathrm{J} / \mathrm{cm}^{2}$, and $120 \mathrm{~J} / \mathrm{cm}^{2}$ on the bottom panel. These four elements 


\section{F.M. Suhaimi et al. / Advances in Science, Technology and Engineering Systems Journal Vol. 3, No. 5, $398-406$ (2018)}

were selected for further comparison across samples as they have more significant values, highly associated with the ablation process, and important element for tooth sample. In this figure, $\mathrm{C}$ is carbon, $\mathrm{O}$ is oxygen, $\mathrm{P}$ is phosphorus, and $\mathrm{Ca}$ is calcium.

Table 7: Identified elements by atomic percentage and weight percentage, before and after laser irradiation of $110 \mathrm{~J} / \mathrm{cm}^{2}$ with wet condition.

\begin{tabular}{|c|c|c|c|c|}
\hline Element & \multicolumn{2}{|c|}{ Before Irradiation } & \multicolumn{2}{c|}{ After Irradiation } \\
\hline & Atomic & Weight & Atomic & Weight \\
\hline $\mathrm{C}$ & 22.59 & 14.93 & 18.57 & 10.18 \\
\hline $\mathrm{O}$ & 60.93 & 53.63 & 48.44 & 35.35 \\
\hline $\mathrm{Na}$ & 0.50 & 0.63 & 0.51 & 0.54 \\
\hline $\mathrm{P}$ & 8.84 & 15.07 & 12.31 & 17.40 \\
\hline $\mathrm{Cl}$ & - & - & 0.55 & 0.89 \\
\hline $\mathrm{Ca}$ & 7.14 & 15.74 & 19.20 & 35.11 \\
\hline $\mathrm{Si}$ & - & - & 0.42 & 0.53 \\
\hline Total & 100.00 & 100.00 & 100.0 & 100.00 \\
\hline
\end{tabular}

There is an abundance of oxygen concerning the atomic and weight percentages before irradiation as observed in Figure 8, followed by carbon, calcium, and phosphorus. However, the percentages of carbon and calcium were varied among these samples, whereas the percentages of phosphorus are about the same. The weight percentage of carbon following irradiation increased tremendously, except for the sample irradiated with a fluence of $110 \mathrm{~J} / \mathrm{cm}^{2}$. After laser irradiation, the percentages of carbon were significantly increased for most of the samples while calcium and oxygen reduced profoundly. Additionally, phosphorus is not majorly changed by the laser irradiation.

In general, the increased and decreased pattern of the four elements with regards to the atomic percentage is about the same across samples. Yet, the percentage differences are highly variable from one sample to another. Only tooth sample that has been irradiated with $110 \mathrm{~J} / \mathrm{cm}^{2}$ has an opposite pattern. These patterns of element changing are almost similar for all the samples presented regardless of the fluence used during the ablation process.

Figure 9 presents the bar charts on atomic and weight percentages of $\mathrm{C}, \mathrm{O}, \mathrm{P}$ and $\mathrm{Ca}$ before irradiation and after irradiation with $80 \mathrm{~J} / \mathrm{cm}^{2}$ and $110 \mathrm{~J} / \mathrm{cm}^{2}$ at wet condition. The trend of tooth sample irradiated with $80 \mathrm{~J} / \mathrm{cm}^{2}$ is similar to the overall trend seen in Figure 8 . Nevertheless, the trend of tooth sample irradiated with $110 \mathrm{~J} / \mathrm{cm}^{2}$ is contrary.

Comparing the same fluence used at $80 \mathrm{~J} / \mathrm{cm}^{2}$ but at different sample conditions, wet and dry, the percentage of carbon increased almost similar. However, the oxygen content of the dry sample is relatively higher compared to the dry sample. However, the changes in oxygen before and after irradiation for both conditions are about the same. In contrast, the percentage difference of calcium before and after irradiation was less for the wet sample. Thus, calcium is not muchly modified by the laser irradiation in the wet condition.
The samples irradiated with $110 \mathrm{~J} / \mathrm{cm}^{2}$ resulted in a lower percentage of carbon either at the wet or dry condition. The percentage of oxygen also decreased eventhough the wet sample has a larger percentage difference before and after laser irradiation. The percentages of phosphorus and calcium are not much different with regards to the wet or dry condition of the sample.

Theoretically, the higher the energy applied to the samples, more interactions occur giving more energy to the atom, and thus resulted into modifications in both morphology and mineral composition. Formation of cracks, shallow pit and fissures can be seen after higher fluence was applied. Nevertheless, wet samples appear uniform, flat, smooth and less crack formation as shown in Figures 6-7. Shallow indentation appearance on dry sample provides information on the rough surface caused by the laser with huge bubbles presented.

Inconsistent results of the tooth elements modifications show that the effect of the laser varies. Technically, it relies on the laser parameters include fluence energy, pulse width and pulse rate. However, the teeth samples used also affect the outcome. Despite the difference fluence used during ablation, the surface morphology and elemental composition of the collected teeth samples were also varied. Thus, the outcome is also expected to be varied, and the difference in the percentages of the elemental composition are assessed to conclude.

Carbon undergoes percentage increment after laser interaction with the samples in almost all fluence energies applied except irradiation at $110 \mathrm{~J} / \mathrm{cm}^{2}$. This explains the undesired carbonization phenomena within the tissues. As the temperature increases, the tissues tend to experience dehydration and eventually burned. Based on the ablation methodology, the absorption of laser beam energy process occurs on the tooth surface makes the surfaces become more carbonize $[15,20]$.

In contrast, carbon composition of the sample irradiated with $110 \mathrm{~J} / \mathrm{cm}^{2}$ experienced reduction, which is unexpected. This might due to the natural condition of the tooth sample. The carbon content of a tooth sample is correlated to several factors include enamel maturity, diets intake and caries susceptibility [21]. Increase caries susceptibility has been associated with the increase in carbon element [22]. Additionally, hypoplastic enamel contains more carbon compared to well-calcified enamel. Thus, the collected samples may vary in terms of enamel density, the number of enamel layers and the weight of enamel layers. In particular, the variation in enamel density results into the variation of optical property and laser absorption of the enamel layer. Thus, the contradict changes in carbon percentage is multifactorial and possibly due to the optical property of the sample itself.

In the case of the sample that has been exposed to a fluence of $80 \mathrm{~J} / \mathrm{cm}^{2}$, the carbon content appears to be the highest, even after the lowest fluence exposure. Photothermal interactions of the laser with tissues include absorption, penetration, scattering and reflection. The undesired carbonization occurs due to the higher interactions with biochemical compounds in the tissue sample. Similarly, this is potentially due to the enamel density and optical property of the sample.

Although the elemental composition might not largely affect, the surface morphology seems to have better form when the 

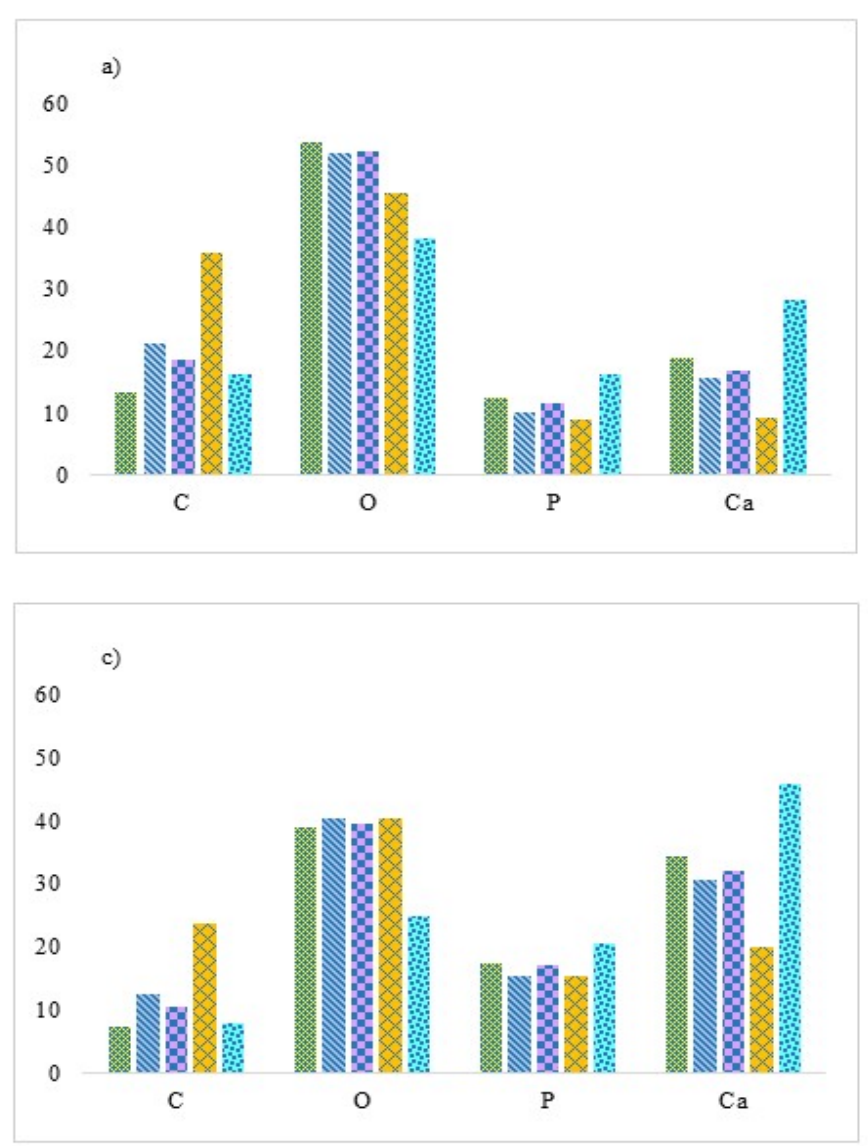

$80 \mathrm{~J} / \mathrm{cm}^{2}$

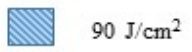

$90 \mathrm{~J} / \mathrm{cm}^{2}$

surface is in the wet condition during laser irradiation. The wet condition of the samples changes the morphological appearance of a tooth surface as shown in Figures 6-7. Rough texture resulted from the dry sample leads to heat generation and thus charring pattern on the tooth surface. At a higher laser fluence, tooth surface may appear with a burning effect and peripheral cracks.

The application of water spray has been associated with low laser-ablation efficiency, as reported in several studies. The use of water spray also ensures the rehydration of mineral contains in the tissue [23]. This is particularly important for Nd:YAG laser ablation in which the influence of the water layer on maintaining the mineral content while preventing stalling and excessive peripheral damage. However, for dental application, the use of water spray is necessary to avoid heat sensation to the patients. A fluence up to $100 \mathrm{~J} / \mathrm{cm}^{2}$ seems acceptable to be used in addition to the wet condition of the sample, as seen from this study.

There are some limitations in this study. It is almost impossible to gather samples that have the similar amount of elemental composition. The compositions are highly variable among all the samples, and some other confounding factors such as enamel density, maturity and calcification may contribute toward the variation. Moreover, morphological appearance of one sample to another was also varied. Some of the samples may have

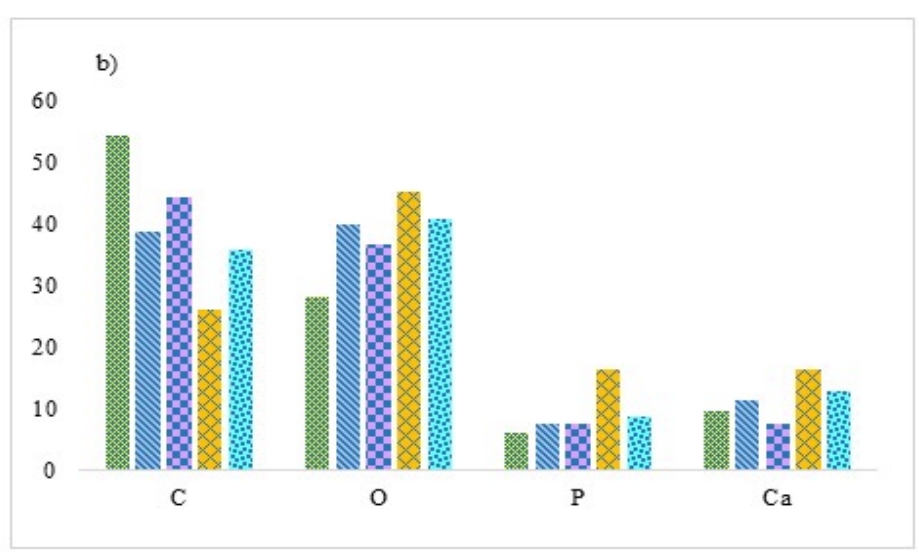

d)

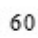

60

50

40

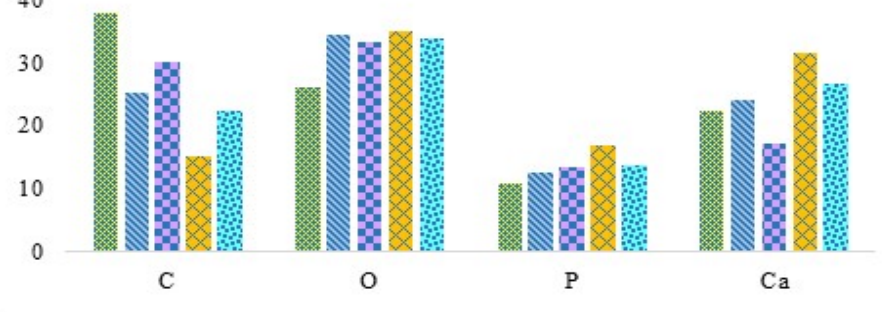

$100 \mathrm{~J} / \mathrm{cm}^{2}$

$110 \mathrm{~J} / \mathrm{cm}^{2}$

$120 \mathrm{~J} / \mathrm{cm}^{2}$ been through a dental treatment which changed the morphological and elemental composition. Thus, comparison of the morphology and elemental composition has to be assessed based on the changes before and after laser irradiation.

As a suggestion, a larger number of samples can provide more statistically significant of the reduction and increment of the elemental composition. Selecting teeth sample from the same subject may reduce the variation. Additionally, the thickness of the sample can be standardized to minimize enamel layer variation, and topography analysis have to be carried out prior to the sample selection. Thus, by considering the sample selection criteria, almost similar or identical enamel characteristics can be selected.

\section{Conclusions}

Laser irradiation affects dental hard tissues physically and chemically as seen from the percentage difference of elemental compositions and the resulting surface morphology of the samples in this study. This study shows that the irradiation of $100 \mathrm{~J} / \mathrm{cm}^{2}$ obtained less damage on enamel surface compared to the results of higher fluence irradiation. In general, the percentage of carbon increased as an effect of the ablation process, whereas the percentage of oxygen decreased. Phosphorus is not significantly 

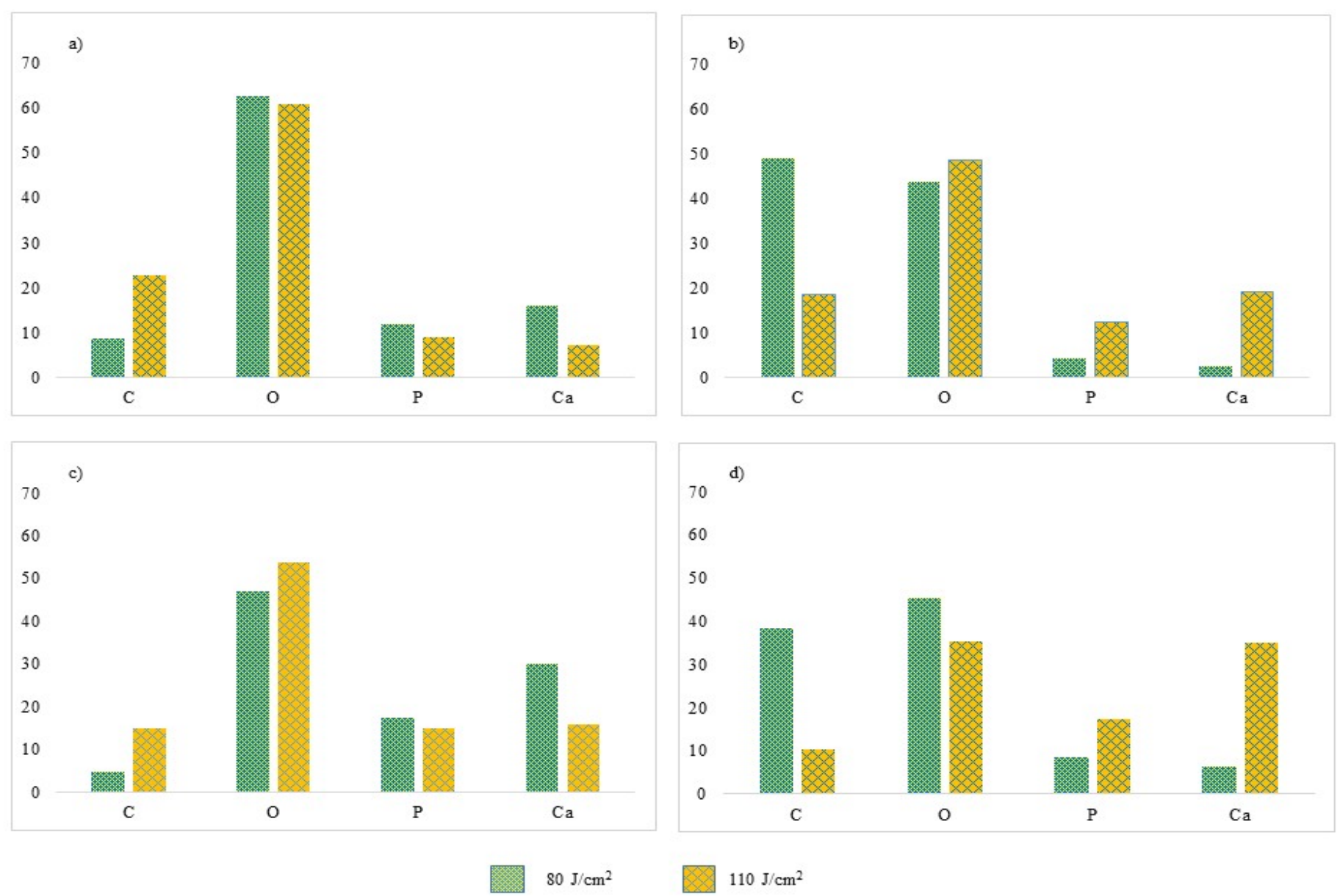

Figure 9: Bar charts of C, O, P and Ca before laser irradiation in terms of a) atomic percentage and b) weight percentage. Bar charts of C, O, P and Ca after laser irradiation of 80 , and $110 \mathrm{~J} / \mathrm{cm}^{2}$ at wet condition in terms of c) atomic percentage and d) weight percentage.

\section{Conflict of Interest}

The authors declare no conflict of interest.

\section{Acknowledgment}

The authors wish to express a profound gratitude to the staffs of Craniofacial and Biomaterial Sciences Cluster, Advanced Medical and Dental Institute and School of Physics, Universiti Sains Malaysia for the support in accomplishing this study. This study is supported by the Short Term Grant from Universiti Sains Malaysia.

\section{References}

[1] S. K. Verma, S. Maheshwari, R. K. Singh, P. K. Chaudhari, "Laser in dentistry: An innovative tool in modern dental practice" Natl J Maxillofac Surg, 3(2): 124-132, 2012. https://doi.org/10.4103/0975-5950.111342

[2] M. Migliario, M. Rizzi, A. G. Lucchina, F. Renò, "Diode laser clinical efficacy and mini-invasivity in surgical exposure of impacted teeth" $\mathrm{J}$ Craniofac Surg., 27(8), 2016. https://doi.org/10.1097/SCS.0000000000003128

[3] Y. Rezaei, H. Bagheri, M. Esmaeilzadeh, "Effects of laser irradiation on caries prevention" J Lasers Med Sci, 2(4):159-64, 2011 http://dx.doi.org/10.22037/2010.v2i4.2710

[4] S. Kasraei, L. Rezaei-Soufi, E. Yarmohamadi, A. Shabani, "Effect of $\mathrm{CO}_{2}$ and $\mathrm{Nd}$ :YAG lasers on shear bond strength of resin cement to zirconia ceramic" J Dent (Tehran), 12(9), 686-694, 2015.

[5] J. Gan, S. Liu, L. Zhou, Y. Wang, J. Guo, C. Huang, "Effect of Nd:YAG laser irradiation pretreatment on the long-term bond strength of etch-and-rinse adhesive to dentin" Oper Dent., 42(1), 62-72, 2017. https://doi.org/10.2341/15-268-L

[6] N. Gutknecht, "State of the Art in Lasers for Dentistry" J. Laser Health Academy, 2008(3), 1-5, 2008.

[7] A. Beketova, N. Poulakis, A. Bakopoulou, T. Zorba, L. Papadopoulou, D. Christofilos, N. Kantiranis, G. A. Zachariadis, E. Kontonasaki, G. A. Kourouklis, at al., "Inducing bioactivity of dental ceramic/bioactive glass composites by Nd:YAG laser" Dent Mater., 32(11), e284-e296, 2016. 10.1016/j.dental.2016.09.029 \}

[8] A. Braun, R. F. Krillke, M. Frentzen, C. Bourauel, H. Stark, F. Schelle, "Heat generation caused by ablation of dental hard tissues with an ultrashort pulse laser (USPL) system" Lasers Med Sci, 30(2), 475-481, 2015. https://doi.org/10.1007/s10103-013-1344-z

[9] A. Braun, R. J. Wehry, O. Brede, C. Dehn, M. Frentzen, F. Schelle "Heat generation caused by ablation of restorative materials with an ultrashort pulse laser (UPSL) system" Lasers Med Sci 27(2), 297-303, 2012. https://doi.org/10.1007/s10103-010-0875-9

[10] L. Kuščer, J. Diaci, "Measurement of ebium laser-ablation efficiency $\mathrm{n}$ hard dental tissues under different water cooling conditions "J Biomed Opt., 18(10), 108002, 2013. https://doi.org/10.1117/1.JBO.18.10.108002 
[11] D. Fried, J. Ragadio, M. Akrivou, J. D. Featherstone, M.W. Murray, K. M. Dickenson, "Dental hard tissue modification and removal using sealed transverse excited atmospheric-pressure lasers operating at lambda $=9.6$ and 0.6 microm" J Biomed Opt, 6(2), 231-238, 2001. https://doi.org/10.1117/1.1344192

[12] R. C. Cecchini, D. M. Zezell, E. de Oliveira, P. M. de Freitas, P. Eduardo Cde, "Effect of Er:YAG laser on enamel acid resistance: morphlogical and atomic spectrometry analysis." Lasers Surg Med, 37(5), 366-72, 2005. https://doi.org/10.1002/lsm.20247

[13] R. Khatavkar, V. Hegde, "Surface analysis of Erbium:YAG laser etching v/s acid etched surface ESEM observations in vitro study" Laser, 2(1), 2010.

[14] S. Al-Jedani, Y. Al-Hadeethi, M. S. Ansari, M. A. N. Razvi, "Dental hard tisssue ablation with laser irradiation" Austin Dental Sciences, 1(1), 1-10, 2016

[15] Y. Al-Hadeethi, S. Al-Jedani, M. A. Razvi, A. Saeed, A. M. Abdel-Daiem, M. S. Ansari, S. S. Babkair, N. A. Salah, A. Al-Mujtaba, "Data fitting to study ablated hard dental tissues by nanosecond laser irradiation" PLoS One, 11(5), e0156093, 2016. https://doi.org/10.1371/journal.pone.0156093

[16] L. E. Rodríguez-Vilchis, R. Contreras-Bulnes, I. Sánchez-Flores, E. C. Samano, "Acid resistance and structural changes of human dental enamel treated with Er:YAG laser" Photomed Laser Surg., 28(2), 207-11, 2010. https://doi.org/10.1089/pho.2008.2454

[17] L. Bartoli, P. Pouli, C. Fotakis, S. Siano, R. Salimbeni, "Charaerization of stone cleaning by Nd:YAG lasers with different pulse duration" Laser Chemistry, 2006 (8175), 1-6, 2006. https://doi.org/10.1155/2006/81750

[18] I. A. Watson, R. K. Wang, I. Peden, G. D. Ward, D. E. S. Stewart-Tull, A. C. Wardlaw, "Effect of laser and environmental parameters on reducing microbial contamination of stainless steel surfaces with Nd:YAG laser irradiation" Journal of Applied Microbiology, 99, 934-44, 205. https://doi.org/10.1111/j.1365-2672.2005.02665.x

[19] F. M. Suhaimi, N. Z. Zainol Alam, S. Mat Ariffin, N. A. Abd. Razak, M. K. A. A. Razab, "Surface modifications of human tooth using Nd:YAG laser for dental applications" 2017 39th Annual International Conference of the IEEE Engineering in Medicine and Biology Society (EMBC), Seogwipo, 2017, 4537-4540. https://doi: 10.1109/EMBC.2017.8037865

[20] W. Raucci Neto, C. P. Lepri, J. J. Faraoni Romano, F. S. Fernandes, de L. M. Castro Raucci, L. Bachmann, R. G. Dibb, "Chemical and Morphological Changes of Primary Teeth Irradiated with Nd:YAG Laser: An Ex Vivo LongTerm Analysis" Photomed Laser Surg., 33(5), 266-73, 2015. https://doi.org/10.1089/pho.2014.3876

[21] M. Sydney-Zax, I. Mayer, D. Deutsch, "Carbonate content in developing human and bovine enamel" J Dent Res., 70(5), 913-6, 1991. https://doi.org/10.1177/00220345910700051001

[22] M. F. Little, F. Brudevold, "A study of the inorganic carbon dioxide in intact human enamel" J Dent Res., 37(6), 991-1000, 1958. https://doi.org/10.1177/00220345580370062001

[23] H. W. Kang, I. Rizoiu, A. J. Welch, "Hard tissue ablation with a sprayassisted mid-IR laser" Phys Med Biol, 52(24), 7243-59, 2007. https://doi.org/10.1088/0031-9155/52/24/004 